\title{
ИЗ ИСТОРИИ СОЦИОКУЛЬТУРНЫХ ОБСЛЕДОВАНИЙ РЕГИОНАЛЬНЫМИ СТАТИСТИЧЕСКИМИ СЛУЖБАМИ (ПО МАТЕРИАЛАМ ДЕЯТЕЛЬНОСТИ СТАТИСТИЧЕСКИХ КОМИТЕТОВ КАЗАХСТАНА КОНЦА ХІХ - НАЧАЛА ХХ В.)
}

\section{FROM THE HISTORY OF SOCIO-CULTURAL SURVEYS BY REGIONAL STATISTICAL SERVICES (BASED ON THE MATERIALS OF THE ACTIVITIES OF THE STATISTICAL COMMITTEES OF KAZAKHSTAN IN THE LATE 19TH - EARLY 20TH CENTURIES)}

Summary: The article systematically presents individual works of the statistical committees of Kazakhstan in terms of the socio-cultural study of the region at the end of the 19th - beginning of the 20th centuries. The objects of study are highlighted, of which the most significant can be attributed: the study of the life of the sedentary and nomadic population, their occupation, economic basis, trade, as well as economic, ethnographic and other conditions for the formation of life. The methodological support of the census campaigns was of great importance, which were largely accompanied by instructional letters and instructions in order to avoid inaccuracies. Much attention was paid to agricultural statistics, the study of the resettlement business, which intensified in the late 19th - early 20 th centuries. The sociocultural surveys carried out in the region made it possible to accumulate unique material, which in many ways became the basis for the design of museums and libraries.

Keywords: history, Kazakhstan, statistical committee, sociocultural research, questionnaire.

\author{
Скопа Виталий Александрович \\ Д.и.н., профессор, Алтайский государственный \\ педагогический университет, г. Барнаул \\ sverhtitan@rambler.ru
}

Аннотация: В статье системно представлены отдельные работы статистических комитетов Казахстана в части социокультурного изучения региона конца XIX - начала XX века. Выделены объекты изучения, из которых к числу наиболее значимых можно отнести: изучение быта оседлого и кочевого населения, их занятия, хозяйственная основа, торговля, а также экономические, этнографические и другие условия формирования жизни. Важное значение имело методическое обеспечение переписных кампаний, которые во многом сопровождались инструкционными письмами и наставлениями, дабы избежать неточности. Большое внимание было уделено сельскохозяйственной статистике, изучению переселенческого дела, которое активизировалось в конце XIX - начале XX вв. Проводимые социокультурные обследования в регионе позволяли накапливать уникальный материал, который во многом становился основой для оформления музеев и библиотек.

Ключевые слова: история, Казахстан, статистический комитет, социокультурное обследование, переписной лист. $\mathrm{y}$ чреждение губернских и областных статистических комитетов и, как следствие, развитие региональной статистической системы, способствовало не только развитию статистического учета в регионе, но и его широкомасштабному научному изучению. Являясь административно-научными центрами, статистические комитеты начали консолидировать передовую общественность региона. Положение 1860 г. «О губернских и областных статистических комитетах» превращало их в научно-административные центры, что закреплялось циркуляром МВД от 8 апреля 1861 года за № 397, в котором выражалось пожелание, «чтобы в делопроизводстве статистических комитетов, как учреждениях административно-ученого, а не просто административного, не было введено лишней административной переписки» $[16$, л. 35].
Степные области населялись различными народностями, мало имевшими общего между собою как по роду жизни, так и по экономическим потребностям, и поэтому не могли рассматриваться как однородные единицы [1]. В них не только каждый уезд, но и каждая волость, каждое селение имели особенности, с которыми статистику приходилось считаться. Хорошо понимая, что комитеты порой являлись единственными научными учреждениями, способными сосредоточить исследования различных сторон жизни, члены их группировали лучшие силы и осуществляли намеченные программы по изучению края [6]. В этих программах ставились задачи, исследуя жизнь во всех её многообразных проявлениях, отражать не одни только факты, но и обусловившие их причины. К тому же рассматриваемый регион имел и стратегическое значение, поэтому изучение действующими стати- 
стическим органами многих объектов являлось всеобъемлющим, разноаспектным и разносторонним.

В этом отношении характерны программы Семипалатинского комитета. С первых лет образования его сотрудники пытались поставить исследования на научную основу, намечали ряд общих и частных программ по изучению края, проводили обследования многих сторон жизни. Их интересовали те изменения, которые происходили в степи. Процессы перехода казахов к оседлой жизни, разложения родового быта, изменения правовых воззрений под влиянием проведенных реформ требовали к себе пристального внимания и своевременного изучения [7]. «Как видоизменяется жизнь киргиза под влиянием разнообразных условий..., чем объясняются печальные проявления этой жизни... - не представляет ли исследование этих вопросов... важности даже с точки зрения непосредственного практического интереса?»писал П. Е. Маковецкий [13, л. 29-30].

Большой человечностью и искренностью чувств проникнуто было его отношение к джетакам. Указывая на их бедственное положение, он писал: «Положение... джетаков никого... не интересует, никому не бросается в глаза, никого не поражает своими особенностями. А между тем эти полуоседлые бедняки заслуживают того, чтобы на них обратить внимание» $[13$, л. 66]. Стоит заметить, что членами комитета прорабатывались переписные формы кочевого и полуоседлого населения.

Интересовало членов комитета и сибирское казачество, составлявшее около 5 процентов населения, его историческая роль, экономические, этнографические и другие условия формирования жизни, отношение его к кочующим на юртовых землях казахам. Большой интерес представляли обычаи, быт, нравы населения переселенческих посёлков, формировавшихся из жителей разных концов России $[8,11]$. В этих условиях на основе взаимного обогащения рождались новые обычаи, создавались новые традиции, которые требовали своевременной фиксации. Особый интерес представляла Александровская волость. Прибывающие переселенцы, увеличивающееся число казахов-землевладельцев, их стремление к расширению запашек - все эти факты заставляли обращать на себя внимание. Столкновение разных элементов отражалось на укладе жизни. Здесь соприкасались самые разные культуры и обычно-правовые понятия. Каждая группа стремилась приноровиться к новому положению, видоизменить свои черты в этом приспособлении, сформировать новый быт. Очень тонко, глубинно и содержательно по этому поводу писал Маковецкий «Мы присутствуем в настоящее время при самом интересном моменте этого процесса, который может дать внимательному наблюдателю в руки богатейший этнографический материал, важнейшие сведения, которых до недавнего времени не было» $[13$, л. 86].
В своих исследованиях комитет стремился учитывать все эти особенности. Однако средства комиссии были ничтожными: общий приход в 1898 г. равнялся 150 руб. $[5,13]$ Не имея материальной возможности для расширения исследовательских работ, большая часть их была приостановлена, а в последствии и вовсе прекращена.

Отдельное внимание Уральский статистический комитет уделял «необязательным» работам, большая часть которых была посвящена быту и занятиям населения [3, 4]. Активная организация данных обследований отчасти объяснялась финансовым благополучием комитета и активностью самих членов, желанием изучить свой регион.

Осенью 1898 года комитет наметил исследование влияния парового транспорта на развитие торговли и промышленности Уральска [3]. Перепись предполагала проверить ряд положений, которые невозможно выяснить другими способами. Обрабатывающие промыслы и торговля под влиянием парового транспорта стали развиваться быстрее, поэтому комитет решил выяснить, какой род промыслов или торговли получил наибольшее развитие. По приблизительным сведениям, за 5 лет с начала действия железной дороги число торгово-промышленных заведений увеличилось на 31,2\%, а их производительность - более чем утроилась. Но за счет каких отраслей произошло увеличение - комитет не мог определить. Железная дорога увеличивала районы ввоза и вывоза товаров, что вело к расширению торговли и промышленности, поэтому комитет наметил выяснить, на какие виды сырья и товаров повысился спрос, показать сближение цен в центре России и в Уральске [10].

Формирование данных сведений производилась при помощи переписных листов, проект которых составил Н.П. Огановокий. В переписной лист было включено 12 вопросов, которые определяли, чью собственность составляет предприятие (одного лица, товарищества, компании, общины, государства), а также сословное положение его хозяина. Выяснив год основания предприятия, можно было определить, какой род промыслов возник под влиянием железнодорожного транспорта [10]. Вопросы о валовом доходе и расходах заведения за 1897 г. необходимы были для определения движения цен, количественных и качественных изменений в торговле, для выяснения видов транспорта и торговых связей Уральска, для описания истории этих связей. Отдельным пунктом было выделено положение рабочих и служащих на предприятиях, их средняя заработная плата, её колебание в зависимости от развития железной дороги, указаны сословие, грамотность, семейное положение, возраст рабочих, продолжительность их рабочего дня [2]. Наконец, сама перепись дала много интересных результатов, которые не предусматривались первоначальным планом: отношение расхода к оборотам в мелких и 
крупных заведениях, число рабочих дней в году, характер и роль горючего материала на предприятиях. Фактически, данные сведения отчетливо можно обозначить как элементы отраслевого статистического учета, что в последствии получит название статистика промышленного производства [14].

Важное значение имело методическое обеспечение переписи, а также инструкционные письма, которые предлагали на места сбора сведений [15]. Для удобства переписи предприятия были распределены на пять групп с оборотом: до 1 тыс. руб. (670 предприятий); до 10 тыс. руб. (471 предприятие); до 50 тыс. руб. (296 предприятий); до 100 тыс. руб. (24 предприятия); свыше 100 тыс. руб. (17 предприятий).

Общее количество предприятий составляло 337 единиц [3]. Конечно, в силу объективных обстоятельств, куда можно отнести нехватку статистиков, ограниченность финансов, обследовать все эти структуры комитет не мог, поэтому он вынужден был ограничиться переписью только третьей, четвертой и пятой групп. В последствии для полноты сформированного материала был составлен исторический очерк развития торговли и промыслов до и после проведения железной дороги, где привлекались архивы областного правления с целью объективной оценки и достоверности.

При переписи применялся только личный опрос. Всего было обследовано 33 рода предприятий, объединенных в 17 групп, но не 337, как предполагалось, а только 163 предприятия. Почти совсем не обследованы остались предприятия, касающиеся торговли лесом, банки и страховые общества: рыбные и лесные склады оказались пустыми, а банки и страховые общества отказались давать сведения [3]. Учитывая недоработку данного учета в 1900 году комитет провёл перепись четырех рыболовецких селений северо-восточного побережья Каспийского моря, которая определила численность населения, главные и побочные занятия, имущество хозяйств [5]. Широко был представлен раздел рыбопромышленности, положения постоянных и сезонных рабочих. В последствии данные сведения были обработанные и опубликованы.

Статистическим исследованиям по программам «необязательных» работ комитеты придавали огромное значение, ибо они отличались большей точностью, как показывала практика, чем текущая статистика. Иногда накопленные материалы становились темой самостоятельных исследований. Так, в 1903 г. Уральский комитет наметил переработать и систематизировать все материалы по области с целью определить уровень и направления её развития. Эта деятельность включала следующие этапы: сбор сведений о демографии и землепользовании; данные о земледелии, скотоводстве и рыболовстве; сведения о торговле и промышленности; материал о платежах и повинностях, о нравственности, здравоохранении и просвещении.

В течение всего 1903 года комитет занимался сбором, систематизацией и обработкой материалов для формирующегося обзора. Всего было обработано около 100000 различных карточек [5]. Полученные сведения, без преувеличения, можно назвать уникальными как в части социокультурного изучения региона, так и сформированных статистических данных, поскольку многие показатели существенно перекрывали ежегодные статистические отчеты и были более достовернее их, а в практической части применимы для административных структур региона.

В 1910 г. комитет, используя накопленный опыт, провел обследование имущества и занятий населения. С этой целью была разработана программа обследования экономического положения каждого двора, из которой исключалось всё, что не представляло индивидуального характера. Таким образом, кроме сведений о составе населения, формируемые переписные листы давали материал о земледелии, о заработках, о состоянии скотоводства, о развитии промыслов и торговли, о климатических, общественных и других условиях развития хозяйств.

Большое внимание уделяли комитеты сельскохозяйственной статистике, изучению переселенческого дела, которое приобретало всё большее значение. Особенно это активизировалось в конце XIX - начале XX вв. Хлынувшая волна переселенцев ставила перед властями ряд проблем, требовавших немедленного разрешения. До образования переселенческих управлений комитетам приходилось заниматься землеотводными работами, регламентацией переселенческого движения, подготовкой обзорных записок. Иногда комитеты намечали целые программы исследования переселенческого дела. Хорошим ориентиром для подобных исследований служила «Программа для собирания сведений о переселенцах», разработанная Н.М. Ядринцевым. Она состояла из двух частей и предусматривала обследования переселенцев, ещё не устроенных, находящихся «в пути», и переселенцев, уже осевших на определенных местах $[12,13]$. Эту программу в той или иной мере использовали многие комитеты Казахстана.

Большая работа по хозяйственному обследованию переселенческих поселков проводилась Семипалатинским комитетом. В 1893 г. для знакомства с переселенческими поселками Усть-Каменогорского уезда был послан Н.Я. Коншин. Из-за недостатка времени и средств он обследовал только 5 поселков в районе Калбинских гор. В каждом из них был произведен подворный опрос, собраны общие сведения, рассматривались посемейные 
списки, на одном из участков казачьей 10-верстной полосы исследованы условия землепользования. По особой программе был произведен посемейный опрос на урочище Корук-Чат, где предполагалось образование поселка с казахским оседлым населением [13].

В следующем году - 1894 Н. Коншин повторил поездку для сбора материалов о быте казахов, проживающих на казачьих землях. Опрос производился при помощи поаульных листов и нехозяйственных карточек. Из-за невозможности опросить всё население он ограничился выбором трех наиболее типичных районов, в которых было развито скотоводство, земледелие или промышленность. Были обследованы: станица Семиярская, поселки Пьяноярский и Григорьевский. Для получения дополнительных сведений проведено обследование в ауле Джаломановском и по сокращенной программе - в Семипалатинской станице и в образованных на 10-верстной полосе казачьих посёлках Азовском, Донском и Таврическом [9]. По результатам обследований Н. Коншин написал ряд работ, по поводу которых в его адрес, как пишет Э. Масанов, раздался грозный окрик генерал-губернатора, но работы были уже опубликованы. Статья же об урочище Корук-Чат «по некоторым причинам» не была опубликована.

В 1894 г. В.П. Никитин провёл подворную перепись поселка Карповского (Современная Восточно-казахстанская область), материалы которой доложены были комитету и помещены в отчете за тот же год. Им же произведен обзор вновь образованных переселенческих поселков Зайсанского, Усть-Каменогорского и Семипалатинского уездов, дан анализ экономического положения населения [13]. Результатом обследований стали его работы «Семипалатинские переселенцы» и «Переселенческое дело в Семипалатинской области». Кроме того, обзор экономического положения переселенческих сёл, состояние переселенческого дела в области даны им в рапорте от 10 ноября 1894 г.

В 1911 г. проведена подворная перепись поселка Георгиевский. Причиной его обследования послужило любопытное сочетание зернового и скотоводческого хозяйства как результат приспособления крестьян к 4 местным естественно-историческим условиям.

В 1891-1892 гг. частичную подворную перепись для выяснения экономического положения крестьян-переселенцев проводил Акмолинский комитет, но такие работы проводились им эпизодично [12].

Начало научно-практическому изучению Тургайской области положено образованием комитета. На первых же заседаниях было решено выработать программу изучения области, создать справочную библиотеку, изучить опыт работы других комитетов. Одной из первоочередных его задач стало исследование положения переселенцев, ибо «эти сведения являются крайне необходимыми для принятия мер к устройству быта их в административном и поземельном отношениях» [18]. К середине 1895 г. созданной комиссией была выработана и опубликована программа работ. Несмотря на скудный бюджет, комитет выделил средства для исследований и издания книги Добромыслова «Скотоводство в Тургайской области» [17]. Были собраны сведения о размерах посевов и сенокосов в Кустанайском уезде, о положении переселенцев в Актюбинском уезде и представлена записка с исследованиями экономического характера и наблюдениями за религиозно-нравственным состоянием русских, живущих среди казахского населения, составленная В.В. Катаринским.

В целом анализ проведенной работы позволяет отметить огромный вклад региональных статистических служб в изучение региона, формирование знаний о нем, а также популяризацию этих знаний среди местного населения. Формируемые статистические сведения во многом являлись существенным подспорьем для действующей административной системы и часто использовались служащими как инструментарий к организации управления. Используемые формы и методы организации и проведения «необязательных» работ позволяли накапливать уникальный материал, который во многом предопределял оформление музеев и библиотек. Социокультурное изучение национальных окраин способствовало более «мягкой» их инкорпорации в состав Российской империи.

\section{ЛИТЕРАТУРА}

1. Алексеенко А.Н. Население Казахстана за 100 лет (1897-1997 гг.). Усть-Каменогорск, 1999. - 128 с.

2. Бюджетное учреждение Омской области «Исторический архив Омской области» Ф. 86. Оп. 1. Д. 63.

3. Ж Журнал заседаний Уральского ОСК 15 февраля 1898 г. Уральск, 1898. - 12 с.

4. Журнал заседаний Уральского ОСК 18 марта 1896 г. Уральск, 1896. - 23 с.

5. Журнал заседаний Уральского ОСК ноябрь 1913 г. Уральск, 1913. - 24 с.

6. Кимасов А.М. Деятельность статистических комитетов Казахстана и их роль в изучении края (1877-1917): автореф. дисс. .. к.и.н. Алма-Ата, 1978. - 21 с.

7. Коншин Н.Я. Очерки экономического быта киргиз Семипалатинской области. Очерк первый. Киргизы на казачьих землях. Семипалатинск, 1901. - 78 с. 
8. Коншин Н.Я. К истории переписи в Семипалатинской области // Семипалатинские областные ведомости. 1898. № 25.

9. Назаров А.И. Очерки по истории фамилий уральских (яицких) казаков. Алматы: Комплекс, 2003. - 180 с.

10. Огановский Н.П. Очерк развития торговли и промышленности в Уральском казачьем войске // Памятная книжка и адрес-календарь Уральской области за 1899 г. Уральск 1900. - С. 117-194.

11. Отчет Тургайского областного статистического комитета. Оренбург, 1896-1898. - 14 с.

12. Республиканское государственное учреждение «Центральный государственный архив» (г. Алматы) Ф. 393. Оп. 1. Д. 1.

13. Республиканское государственное учреждение «Центральный государственный архив» (г. Алматы) Ф. 460. 0п. 1. Д. 2.

14. Фастов К.Л. Из истории сельскохозяйственной статистики // Учёные записки Куйбышевского университета. Куйбышев, 1958. - 326 с.

15. Скопа В.А. К проблеме инструкционного руководства по заполнению переписных форм (по материалам статистических обследований Томской губернии в конце XIX - начале XX вв.) // Документ как социокультурный феномен. (борник материалов IV Всероссийской научно-практической конференции с международным участием. Министерство образования и науки Российской Федерации, Федеральное агентство по образованию, Томский государственный университет, Архивное управление Томской области; Ответственный редактор Н.С. Ларьков. 2010. - С.274-276.

16. Российский государственный исторический архив Ф. 1290. Оп. 1. Д. 37.

17. Добромыслов А.И. Краткие географические сведения о Тургайской области. Оренбург, 1894. 42 с.

18. Журнал заседаний Тургайского ОСК за 1902 г. Оренбург, 1902. 35 с.

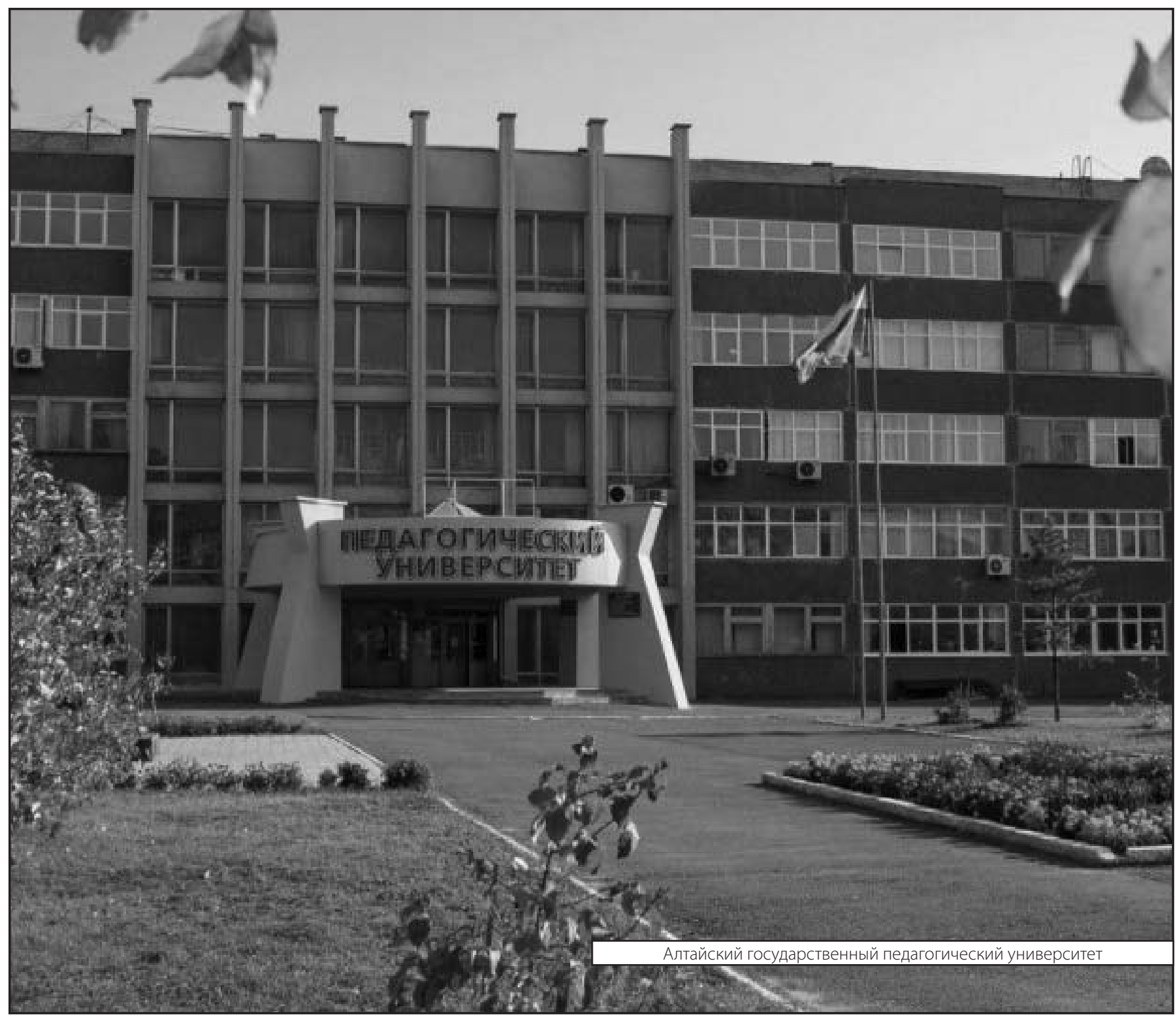

